\title{
RELAÇÃO OBRIGACIONAL ENTRE MÉDICO-PACIENTE: MEDICAMENTOS “OFF-LABEL” E RESPONSABILIDADE CIVIL
}

\author{
Daniel Marinho Corrêa* \\ Ana Cláudia Zuin Mattos do Amaral ${ }^{* *}$
}

RESUMO: Em tempos pandêmicos ocasionados pelo coronavírus, verifica-se a ausência de tratamentos eficazes; com a urgência e a necessidade nascidas da desesperança, muitos recorrem para o uso de terapias não comprovadas, como a hidroxicloroquina, para as quais existem poucas evidências de eficácia. Nesse cenário, constata-se que não existe distinção na responsabilidade por prescrição "off-label" na conjuntura pandêmica e fora desta, no que concerne às suas consequências jurídicas no campo da responsabilidade civil. Utilizando-se o método dedutivo, confirma-se que as regras legislativas presentes no sistema jurídico brasileiro vão ao encontro do disposto no direito comparado, caminhando para a responsabilidade objetiva do médico.

PALAVRAS-CHAVE: Obrigação de meio. Obrigação de resultado. Responsabilidade civil. Medicamentos "off-label”. COVID-19.

\section{OBLIGATORY RELATIONSHIP BETWEEN DOCTOR-PATIENT: OFF-LABEL" MEDICINES AND LIABILITY}

\begin{abstract}
In times of coronavirus pandemic, there is a lack of effective treatments; urgency and the need born of hopelessness, many call for the use of unproven therapies, such as hydroxychloroquine, for which there is little evidence of effectiveness. This scenario, appears that there is no distinction in liability for prescription "off-label" in the pandemic context and outside, with regard to its legal consequences in the field of civil liability. Using the deductive method, it is confirmed that the legislative rules present in the Brazilian legal system meet the provisions of comparative law, walking to the strict liability of the doctor.
\end{abstract}

KEYWORDS: Obligation of means. Result obligation. Liability. Off-label medications. COVID-19.

\section{INTRODUÇÃO}

\footnotetext{
* Professor, servidor do TJPR e mediador judicial. Mestrando em Direito Negocial pela Universidade Estadual de Londrina, extensão pela Harvard University e especialista em Direito Civil e Empresarial pela Faculdade Damásio. Endereço eletrônico: danielmarinhocorrea@ gmail.com.

** Professora do Programa de Mestrado e do Curso de Graduação e Pós-Graduação em Direito da UEL. Doutora em Direito das Relações Sociais pela PUC-SP. Mestrado em Direito Negocial. Endereço eletrônico: anaclaudiazuin@live.com.
} 
Sabe-se que têm sido grandes os avanços tecnológicos e científicos na área da saúde, todos desenvolvidos com um único propósito: melhorar a qualidade de vida dos pacientes e, em muitos casos, prolongar a existência humana.

Por outro lado, com o surpreendente avanço da COVID-19, dificilmente se poderia imaginar a fragilidade da civilização vigente, bem como que a realidade pudesse ser mudada de uma maneira tão surpreendente. No campo da saúde, em particular, surgem ainda mais preocupações relacionadas ao tema.

Os médicos e em geral todos os profissionais da área da saúde são treinados sob dois grandes princípios: beneficência e não maleficência, ou seja, fazer o bem, mas, acima de tudo, evitar prejudicar o paciente.

A prescrição de medicamentos é um ato médico complexo, atravessado por múltiplas circunstâncias e interesses diversos: a ilusão social e o desejo crescente de consumo, o impacto nos custos da saúde, o interesse da indústria farmacêutica e a integridade profissional, entre outros. Como se não bastasse essa complexidade da prescrição, em tempos de pandemia, ela se torna ainda mais difícil.

A Organização Mundial da Saúde (OMS), atenta a essas circunstâncias, à complexidade e às consequências do ato de prescrever, promove o uso racional do medicamento, quando o paciente recebe a medicação adequada às suas necessidades clínicas, em dose, prazo, tempo e com o menor custo para o paciente e a comunidade.

A responsabilidade associada ao ato de prescrever é um acontecimento recente, pois na antiguidade o médico preparava, prescrevia e dispensava medicamentos; nestes tempos, a produção, distribuição e abastecimento são feitos através da farmacoindústria, drogarias e farmacêutico, respetivamente.

O surgimento de novas especialidades medicinais e o desenvolvimento de pesquisas farmacoclínicas também são fenômenos relativamente recentes; até o século XX a maioria dos medicamentos disponíveis eram formulações de origem natural e preparações de tipo magistral.

Hodiernamente, o grande número de medicamentos disponíveis aumenta a complexidade do ato de prescrever; onde convergem múltiplas variáveis técnico-científicas e deveres ético-legais de destaque; soma-se a isso tudo a pandemia do novo coronavírus. Logo, diante de uma possível falibilidade médica, verificar-se-á qual responsabilidade civil nesse panorama. 
A responsabilidade civil está em constante alargamento seguindo a evolução social no confronto dos problemas que lhes são atribuídos a cada dia. Em face da fatalidade e das sequelas que podem despontar em virtude da COVID-19, esse cenário pode ser ainda maior, de modo que as questões tangenciadas por esse instituto civil são vastas.

Dessa maneira, possibilitar-se-á deduzir se o ordenamento atual é adequado para a responsabilização do médico quando da prescrição "off-label" dos medicamentos para o tratamento da COVID-19. Se positiva a indagação, os impactos da pandemia na intervenção de pacientes afetados pelo novo coronavírus, sejam quais forem os percebidos em casos concretos, constituirão uma diferenciação (ou não) na responsabilidade por esse tipo de prescrição em situação de pandemia.

\section{A RELAÇÃO OBRIGACIONAL ENTRE MÉDICO-PACIENTE}

Entre médico e paciente há uma relação de bilateralidade, na qual ambos têm direitos e deveres. Ademais, a orientação adequada do clínico e o consequente cumprimento das obrigações médicas pelo paciente durante seu tratamento, devem ser vistas como parte fundamental na obtenção de resultados.

Antes de entrar na seara da responsabilidade civil propriamente dita, apresenta-se as espécies das obrigações em meio e de resultado, dicotomia recente, advinda com a acentuação das relações de consumo, e tem estreita ligação com as duas teorias que classificam a responsabilidade civil.

Outrora, à responsabilidade civil era aplicada apenas a teoria subjetiva. No entanto, com o crescimento das relações de consumo após a Revolução Industrial, os indivíduos passaram a não aceitar mais tão facilmente os prejuízos que poderiam levar em relação à aquisição de produtos ou contratação de serviços, dando ensejo à teoria objetiva e, consequentemente, uma modificação nas relações obrigacionais, que culminou com a classificação ora em estudo.

Introduzida por Demogue, na doutrina francesa moderna, modificada por Henri e Léon Mazeaud, que a consideravam uma summa divisio de todas as obrigações, delituais e contratuais, a distinção entre obrigações de resultado e de meios diz respeito ao objeto da obrigação, tendo, contudo, por razão de ser, uma repartição diferente do ônus da prova que incumbe aos contratantes, por ocasião de uma contestação (TUNC, 1989, p. 748). 
Consequentemente, definiu-se um liame entre a responsabilidade civil e a teoria geral das obrigações, relacionando-se a responsabilidade civil objetiva com a obrigação de resultado e a responsabilidade civil subjetiva com a obrigação de meio.

Em relação à atividade médica, a importância primária do assunto deve-se ao fato de que tanto as clínicas quanto os médicos estão sujeitos à imputação de responsabilidade por qualquer dano causado por erro cometido durante a prática dos procedimentos a que forem contratados, em decorrência do descumprimento de obrigações assumidas. Para tanto, é de extrema necessidade a verificação da natureza da obrigação incidente, ainda mais se levarmos em consideração que é tal diferenciação que confere lógica ao sistema contratual, mormente quando se cuida de responsabilização pelo inadimplemento da obrigação pactuada.

A partir do artigo 1315 do Código Civil Francês ${ }^{1}$, André Tunc (1989, p. 748) justifica a distinção ora em exame, no sentido de que a pessoa vinculada a uma obrigação de resultado deveria demonstrar a execução do fato capaz de extinguir a obrigação, enquanto que a responsabilidade do obrigado por diligência não incidiria, salvo na hipótese de o próprio credor provar a inexecução. O autor recorre a um exemplo clássico: versa a obrigação do médico em fornecer ao paciente cuidados conscienciosos, vigilantes, ajustado aos dados científicos. Sua responsabilidade não seria demandada de pleno direito em face de um disparo cruel da doença, de modo que seria necessário provar contra o médico uma culpa determinada.

Sintetiza Caio Mario da Silva Pereira (1993, p. 214) que nas obrigações de resultado “a execução considera-se atingida quando o devedor cumpre objetivo final; nas de meio, a inexecução caracteriza-se pelo desvio de certa conduta ou omissão de certas precauções a que alguém se comprometeu, sem se cogitar do resultado final”.

Logo, as obrigações qualificadas como de resultado o foco centra-se na verificação se o propósito pretendido pelo contratante foi alcançado, quando, então, considera-se a obrigação como cumprida. Por sua vez, nas obrigações de meio, a necessidade é de se averiguar se o devedor aplicou todos os elementos possíveis para garantir o melhor cumprimento da obrigação, se foi diligente ao desempenhar seu compromisso para com o seu credor. Ainda a título de diferenciação e fazendo-se presente a relação de tal classificação com as teorias sobre a responsabilidade civil, afirma que nas obrigações de resultado o inadimplemento dá ensejo a

\footnotetext{
${ }^{1}$ Do original: "Celui que reclame l'exécution d'une obligation, doit la prouver. Réciproquement, celui qui se prétend libéré, doit justifier le paiement ou le fait qui a produit l'extinction de son obligation". Traduzido livremente: "Aquele que reclama a execução de uma obrigação deve prová-la. Reciprocamente, aquele que se pretende liberado, deve justificar o pagamento ou o fato que produziu a extinção de sua obrigação."
} 
uma falta contratual com presunção de culpa, isto é, não há necessidade de aferi-la frente ao descumprimento de um contrato, pelo fato da culpa, em tal caso, configurar-se como objetiva; de outro vértice, ressalva-se que nas obrigações de meio o inadimplemento deve ser analisado com base na própria conduta do devedor, cabendo ao credor provar a culpa do devedor (VENOSA, 2003, pp. 80-83).

Por outro lado, André Tunc (1989, p. 758) considera que a obrigação de diligência pode ser encontrada, com frequência, como obrigação acessória de uma obrigação de resultado, sendo esta estabelecida no instrumento contratual como principal.

A atividade do profissional liberal, especificamente a atividade do médico, em regra, constitui-se em "uma obrigação de meio e não de resultado, por não comportar o dever de curar o paciente, mas sim o de prestar-lhe os cuidados conscienciosos e atentos conforme os progressos da medicina" (DINIZ, 2013, p. 299). Portanto, o médico se obriga a dispor de meios para chegar a um resultado extrínseco ao contrato.

Por outro lado, existem situações em que a atividade do médico pode ensejar obrigação de resultado, como, por exemplo, na cirurgia plástica estética, em cirurgias de correção da visão, bem como em exames laboratoriais. Nesses casos, não se pode deixar de considerar que o médico ou a clínica pode elaborar um instrumento contratual de prestação de serviços, com previsão de possibilidade de intercorrências danosas, e assim proceda com o intuito de caracterizar a sua atividade/obrigação como de meio, desvirtuando, assim, a natureza da obrigação, que é de resultado.

Ampla problemática há a respeito das relações entre médico-paciente na prescrição “off-label” de medicamentos. Para Fabrício Zamprogna Matielo (1998, p. 53) as obrigações de meio vinculam "o profissional à aplicação diligente de todos os recursos disponíveis para a melhor condução possível do caso clínico, que será alvo de seus préstimos".

Logo, mesmo considerando o serviço prestado pelo profissional da medicina uma obrigação de meio, ao prescrever um medicamento sem comprovação para a respectiva doença, o médico não estaria agindo dentro da prudência. Isso porque a prescrição de medicamentos não é apenas um ato dirigido a uma determinada pessoa, o paciente; mas também pode levar a consequências gerais: geração de expectativas para o grupo afetado pela mesma patologia, impacto nos custos de saúde, modificação dos limites de cobertura do seguro saúde, entre outros.

Por outro lado, pode-se entender por obrigação de resultado quando o médico conhece 
os efeitos nocivos do medicamento e mesmo assim o prescreve:

Cuando el médico conoce los efectos nocivos del producto por la advertencia expresa contenida en el envase del medicamento o que surge de las publicaciones que a tal fin hacen circular las empresas farmacéuticas: en este caso la responsabilidad surge (...), pues actúa como "intermediario versado en la materia" entre el fabricante y el consumidor. Algunos opinan que la obligación es de resultado, pues para descartar la culpa incumbe al profesional demostrar que prestó adecuadamente el servicio. Otros entienden que se trata de una obligación de resultado atenuada, ya que el factor de atribución es subjetivo con inversión de la carga de la prueba (GUTIÉRREZ, 1997, p. 15).

Por isso, o ato médico de prescrição de medicamentos deve ser realizado com adequado conhecimento do perfil farmacológico, segurança, eficácia, efetividade, qualidade, conveniência e custo das alternativas medicamentosas existentes e aprovadas pelos órgãos reguladores.

\section{RESPONSABILIDADE CIVIL: DOS ASPECTOS GERAIS ÀS NORMAS E RECOMENDAÇÕES PARA A PRESCRIÇÃO DE MEDICAMENTOS}

A ordem jurídica contemporânea visa a proteção do lícito e a repressão do ilícito para alcançar tal fim, são situados deveres jurídicos. A transgressão a certo dever jurídico configura o ilícito, que pode causar um dano a alguém, provocando uma nova obrigação: reparar o dano.

A partir disso extrai-se a noção de responsabilidade civil, "um dever jurídico sucessivo que surge para recompor o dano decorrente da violação de um jurídico originário" (CAVALIERI FILHO, 2003, p. 26).

O Código Civil de 2002 adotou os sistemas da responsabilidade civil subjetiva e objetiva. Se de um lado, entende-se não ser aceitável a prevalência de um desses sistemas (NERY JÚNIOR; NERY, 2005, p. 535), de outro, afirma-se que a regra é da responsabilidade subjetiva e a responsabilidade objetiva seria exceção (VENOSA, 2003, p. 12).

Conforme a espécie de reponsabilidade civil incidente altera-se os pressupostos, pois a comprovação de culpa é necessária, exclusivamente, na reponsabilidade civil subjetiva. Ainda, a ação e a omissão, a relação de causalidade ou nexo causal e o dano, são outros pressupostos que devem se fazer presentes nas duas espécies de responsabilidade.

Os dois sistemas coexistem no Código Civil e a reponsabilidade, se fundada no risco, 
seria objetiva, pois constituída no princípio da equidade; significando que aquele que lucra com uma situação tem o dever de responder pelos riscos ou pelas desvantagens dela consequentes (GONÇALVES, 2003, p. 22). Assim, uma atividade exercida por alguém com potencialidade de causar riscos à vida ou a saúde de outro, é considerada lesiva, o que dá ensejo ao ressarcimento de futura lesão, independentemente da prova de culpa do agente.

Posta desse modo a questão, o dever de indenizar, na responsabilidade objetiva com fundamento no risco, surge, não só em decorrência de atos ilícitos, mas também como decorrência da prática de atos lícitos.

O paradigma da medicina baseada em evidências, aliado ao adequado julgamento clínico, permite ao médico exercer uma prática diligente na prescrição de medicamentos. A resposta e a adesão ao medicamento prescrito devem ser avaliadas de acordo com a história particular de cada paciente "cuando el médico desoyendo las advertencias suficientes del producto, se aparta de éstas y asume el riesgo de prescribirlo: en este caso es responsable (GUTIÉRREZ, 1997, p. 16).

O erro do médico ao prescrever um medicamento com efeitos nocivos reconhecíveis constitui um inequívoco indesculpável, uma vez que as informações prestadas pelo fabricante, juntamente com o dever de atualização permanente, por meio da bibliografia disponível e do acesso ao sistema de farmacovigilância, são elementos disponíveis para o profissional responsável pelo tratamento.

Por outro lado, há circunstâncias em que a atividade médica tem como fim um resultado, nesses casos, a responsabilidade pode vir posta em um instrumento contratual. Já na responsabilidade extracontratual, ou aquiliana, existe a prática de um ato ilícito, que causa lesão a outrem, sem que exista entre o ofensor e o ofendido qualquer relação pretérita. Embora as duas espécies sejam reguladas pelos mesmos princípios, se faz forçosa a distinção entre elas, em face de suas causas diversas e das diferenças no que tange ao ônus da prova (DONNINI, 2004, pp. 20-26).

Nesse último caso, clara diferença existe entre os dois tipos de responsabilidade: na contratual, comprovando o credor a inadimplência da obrigação pelo devedor, fica este com o ônus de provar a ausência de culpa ou mesmo de qualquer outro fato que exclua sua responsabilidade; no caso da reponsabilidade extracontratual, o ônus probatório cabe ao ofendido, tanto da culpa, se exigida, quanto do dano e do nexo de causalidade.

Por sua vez, a Lei $n^{\circ} 8.078$ de 1990 instituiu, em conformidade com os artigos $5^{\circ}$, 
inciso XXXII, e 170, inciso V, ambos da Constituição Federal, o Código de Defesa do Consumidor que, partindo da premissa basilar de que o consumidor é o elemento vulnerável das relações de consumo e primando por restabelecer o equilíbrio em tal relação, adotou, como regra, a reponsabilidade objetiva.

Referido diploma, quando equiparou em seu artigo 17 o consumidor de um produto ou serviço a todas as vítimas de um acidente de consumo, superou a antiga distinção entre reponsabilidade contratual e extracontratual.

\begin{abstract}
Realmente, a responsabilidade do fornecedor em seus aspectos contratuais e extracontratuais, presentes nas normas do Código de Defesa do Consumidor (arts. 12 a 27), está objetividade, isto é, concentrada no produto ou no serviço prestado, concentrada na existência de um defeito (falha na segurança) ou na existência de um vício (falha na adequação, na prestabilidade). [...] Assim, os produtos ou serviços prestados trariam em si uma garantia de adequação para o seu uso e, até mesmo, uma garantia referente à segurança que deles se espera. Há efetivamente um novo dever de qualidade instituído pelo sistema do Código de Defesa do Consumidor, um novo dever anexo (MARQUES; BENJAMIN; MIRAGEM, 2004, p. 223).
\end{abstract}

Nesse ponto, para que exista a responsabilidade do fornecedor necessária se faz a constatação do defeito ou vício, do dano e do nexo causal. Concomitantemente, o Código de Defesa do Consumidor estabeleceu uma obrigação de qualidade à atividade dos fornecedores, alusiva não apenas à adequação dos bens e serviços, mas também à segurança que deles se confia.

Pela teoria do risco do empreendimento, todo aquele que se disponha a exercer alguma atividade no mercado de consumo tem o dever de responder pelos eventuais vícios e defeitos dos bens e serviços fornecidos, independentemente de culpa. Este dever é imanente ao dever de obediência às normas técnicas e de segurança, bem como aos critérios de lealdade, quer perante os bens e serviços ofertados, quer perante os destinatários dessas ofertas [...] (CAVALIERI FILHO, 2003, p. 473).

Essas relações de consumo se perfazem sempre que houver a existência de três elementos, quais sejam: o consumidor, o fornecedor e a aquisição de um produto ou serviço. Dado que a Lei n. 8.078/90 se introduz também com os princípios de ordem pública e interesse social, suas normas se sobrepõem em face da vontade dos indivíduos da relação de consumo, dentro de seus comandos cogentes e nos contornos por ela tracejados, de modo que se permite 
ao juiz a aplicação dessas regras de ofício, ou seja, independentemente do pedido das partes (NUNES, 2000, p. 76).

Destarte, a relação entre médico e paciente é manifestamente uma relação de consumo, de modo que presente os três elementos, quais sejam: o consumidor (paciente), o fornecedor (médico), que é o detentor de um conhecimento técnico indispensável para exercer sua atividade, proporcionando um serviço especializado (terceiro elemento). Dispõe o $\operatorname{artigo} 1^{\circ}$ da Resolução n. 1.627/2001 do Conselho Federal de Medicina que ato médico é procedimento técnico-profissional exercido por médico legalmente habilitado com o seguinte fim: "a promoção da saúde e prevenção da ocorrência de enfermidades ou profilaxia; a prevenção da evolução das enfermidades ou execução de procedimentos diagnósticos ou terapêuticos; a prevenção da invalidez ou reabilitação dos enfermos."

O médico é um prestador de serviço à saúde de seus pacientes, que se faz por intermédio de um pagamento. Esse conceito se acomoda com o de fornecedor de serviços previsto no artigo $3^{\circ}$ do Código de Defesa do Consumidor, in verbis: "fornecedor é toda pessoa física ou jurídica (...) que desenvolvem atividade de produção, montagem, criação, construção, transformação, importação, exportação, distribuição ou comercialização de produtos ou prestação de serviços."

A condição de consumidor é reconhecida ao paciente, que busca com o serviço adquirido a promoção de sua saúde. Ficando evidenciada a relação consumerista, pois figurase "o profissional da saúde como fornecedor e o cliente como consumidor" (CASTRO, 2005, p. 93).

Portanto, sendo essa relação (médico-paciente) de consumo, as normas de ordem pública e interesse social referente à tutela consumerista merecem aplicação. Esse também é o entendimento do Superior Tribunal de Justiça, que em julgamento do Recurso Especial de n. 364.168, definiu pela aplicação do Código de Defesa do Consumidor aos profissionais liberais, incluindo os médicos.

Avulta-se, entretanto, que tal relação, embora consumerista, não afasta, de forma absoluta, a aplicação do Código Civil. O próprio CDC, em seu artigo $7^{\circ}$, aduz que os direitos nele previstos "não excluem outros decorrentes (...) da legislação interna ordinária, de regulamentos expedidos pelas autoridades administrativas competentes, bem como dos que derivem dos princípios gerais do direito, analogia, costumes e equidade."

Evidenciada a incidência do Código de Defesa do Consumidor nas relações entre 
médicos e pacientes, anota-se que, como consequência disso, que o sistema de reponsabilidade civil objetivo será aplicado em tais relações, observadas as hipóteses em que, em face do diálogo das fontes, diferentes normas e princípios devam advir no referido microssistema, visando, exclusivamente, à proteção do consumidor.

Em que pese essas disposições legais, a regulamentação sobre o uso de medicamentos na modalidade "off label” é praticamente inexistente. Em poucas manifestações sobre o assunto, a agência brasileira de controle de medicamentos, ANVISA (2005), por meio da Gestão de Novos Medicamentos, Pesquisa e Ensaios Clínicos, deu a conhecer sua opinião.

Em primeiro lugar, explica que a eficácia e segurança dos medicamentos são comprovadas por meio de estudos clínicos e que, de acordo com os resultados, procedem ao registro e autorização de comercialização. Esclarece, então, que quando um medicamento é aprovado para determinada indicação, isso não significa que esta seja a única possível, e que o medicamento só pode ser utilizado para essa indicação.

O comunicado continua informando que outras indicações podem ser ou serão estudadas e posteriormente apresentadas à agência para aprovação. Os estudos poderão ser realizados após a aprovação da primeira indicação, para estender seu uso a outra faixa etária, para uma fase diferente da mesma enfermidade (outrora aprovada), para outra moléstia, ou até mesmo para um uso mais restritivo do que a autorização inicial.

A ANVISA (2005) informa ainda que enquanto as novas indicações não forem aprovadas, seja por informações incompletas ou porque o órgão regulador está avaliando o pedido, o médico pode prescrever um medicamento com indicação ainda não aprovada, seja por patologias semelhantes ou análogas. Por fim, a agência estabelece que "o uso off label é, por definição, não autorizado por uma agência reguladora, mas isso não implica que seja incorreto".

\section{RESPONSABILIDADE CIVIL DO MÉDICO NA PRESCRIÇÃO DE MEDICAMENTOS EM INDICAÇÕES NÃO APROVADAS (USO “OFF LABEL")}

No aspecto da saúde, a pandemia de COVID-19 tem implicações dramáticas. Em solo brasileiro, desde os primeiros dias de sua disseminação, a inadequação do Sistema Único de Saúde (SUS) para reagir à propagação repentina do vírus entre a população ficou manifesta. O número insuficiente de provisões técnicas (dispositivos de proteção individual, hospitais, leitos 
e respiradores artificiais) e a escassez de pessoal de saúde para lidar com o número grande de pacientes foram os principais problemas com os quais os responsáveis pelo gerenciamento da emergência tiveram que lidar.

Nessa conjuntura e em face do que já foi exposto, necessário evidenciar qual a responsabilidade civil dos médicos na prescrição dos medicamentos "off-label” em virtude da COVID-19.

O uso de um medicamento "off label" é a prática da prescrição de drogas farmacêuticas sob condições diferentes das autorizadas. Por exemplo, o uso da Cloroquina ou de seu análogo, a Hidroxicloroquina (medicamento liberado pela ANVISA para doenças como a malária) para o tratamento dos casos de coronavírus é um exemplo de uso assistencial fora da sua indicação terapêutica aprovada:

O uso "off label" é realizado por um médico assistente tendo em vista o benefício que este medicamento, fora de suas prescrições autorizadas, pode acarretar ao seu paciente assistencial. Este benefício deve ser cotejado contra os riscos associados ao seu uso, que já estão descritos na literatura médica e no próprio processo de liberação do produto. A cloroquina é um medicamento muito conhecido, quando utilizado nas suas indicações usuais, e apresenta inúmeros riscos de eventos adversos graves e esperados, já descritos na sua própria bula (GOLDIM, 2020).

Trazendo contribuições do direito comparado, em Portugal, a possibilidade da prescrição "off-label” deriva do princípio da liberdade profissional do médico, bem como do princípio da liberdade de escolha dos meios de diagnóstico e tratamento, dispostos no art. $7^{\circ}$ do Código Deontológico da Ordem dos Médicos (2016):

Artigo $7 .^{\circ}$ - Isenção e liberdade profissionais. 1. O médico só deve tomar decisões ditadas pela ciência e pela sua consciência. 2. O médico tem liberdade de escolha de meios de diagnóstico e terapêutica, devendo, porém, abster -se de prescrever desnecessariamente exames ou tratamentos onerosos ou de realizar atos médicos supérfluos.

De seu turno, nos Estados Unidos da América, país do common law, tem-se no julgamento do caso Klein v. Biscup, proferido em Ohio em 1996, a garantia de que cumpre ao médico instituir a prescrição do medicamento "off-label", tendo este tão somente a obrigação de comunicar ao paciente sobre o status regulamentar da droga perante a Food and Drug Administration (FDA), agência reguladora semelhante a ANVISA (Agência Nacional de 
Vigilância Sanitária), no Brasil. Por outro lado, caso o clínico atue com negligência no uso desses medicamentos, estaria sujeito à responsabilidade.

Esse precedente norte-americano, em que pesa não obrigue ao médico o fornecimento de informações completas aos pacientes a respeitos dos potenciais riscos dessas drogas, não o exime do dever de noticiar aqueles perigos essencial na sua administração (EUA, 1996).

No Brasil, o Código de Ética Médica brasileira (2018), em seu artigo 20, traz normatização semelhante ao diploma português, proibindo que médico permita que interesses "pecuniários, políticos, religiosos ou de quaisquer outras ordens, do seu empregador ou superior hierárquico ou do financiador público ou privado da assistência à saúde", intervenham na opção das melhores vias de "prevenção, diagnóstico ou tratamento disponíveis e cientificamente reconhecidos no interesse da saúde do paciente ou da sociedade".

Ademais, a essas inovações terapêuticas são aplicados princípios que dirigem o direito da experimentação em um ser humano, de modo que deve existir uma informação precisa ao paciente:

[...] um "acentuado dever de informação", por respeito ao princípio da autonomia, que mantém toda a sua vigência num período de exceção, mesmo em casos em que não há medicação autorizada para um vírus novo e, caso o paciente já esteja incapaz de consentir, seja assegurada a autorização; o respeito pelo "princípio da beneficência", a implicar que o médico só deve propor uma inovação terapêutica, se perante o quadro clínico que tem em mãos, não dispuser de um método seguro e eficaz já devidamente consagrado; em nome do princípio da transparência, deve a prescrição e sua fundamentação ser "registada no processo clínico" (PEREIRA, 2020, p. 141).

Nesse contexto, o princípio da precaução ganha prestígio, na medida em que uma intervenção médica desvia do seu padrão, quando utiliza desses medicamentos "off-label”. Embora seja lícito seu uso, tendo em vista o princípio da beneficência e não da maleficência, deve-se respeitar a autonomia do paciente. Diante disso, são elaborados pressupostos para utilização desses medicamentos:

[...] (1) um "consentimento informado reforçado", (2) uma justificada "análise risco-benefício" da sua utilização no paciente concreto, (3) com referência a estudos que permitam uma cabal "fundamentação científica". (4) o médico deve "registar", pelo menos no caso de intervenções com riscos ou consequências secundárias mais graves, um esboço dessa fundamentação no processo clínico do doente; (5) a decisão de recurso a "prescrição off-label" resulte de uma decisão partilhada, primeiro, em "equipa médica", segundo, 
com o "próprio doente"; (6) só em casos extremos se poderá lançar mão do "consentimento presumido". (7) Só se poderá legitimar a inovação terapêutica após uma cuidadosa "ponderação custo-benefício" e (8) em caso algum se pode privar o doente de tratamento fundamental (PEREIRA, 2020, p. 142).

Sob o aspecto da responsabilidade civil, pode-se assegurar que os danos suportados pelo paciente em face da prescrição "off-label”, não podem ser imputados ao laboratório fabricante. No tocante a relação obrigacional entre médico e paciente, embora a administração desses medicamentos não seja proibida no Brasil, essa pretensão será dirigida ao médico.

Logo, a responsabilidade médica no Direito brasileiro, mesmo em contexto de pandemia, permanece sendo objetiva. Por outro lado, situações excepcionais, extraordinárias e inevitáveis (casos fortuitos ou força maior), afastam a imputação da responsabilidade ainda que se adote a teoria do risco, pois não estaríamos em uma situação de risco integral (CASTRONOVO, 2018, p. 458).

O que muda, em cenário de crise decorrente da pandemia, é o menor rigor na análise da correção ou incorreção da conduta profissional na execução do ato médico.

Na situação de crise, como a ocasionada pela pandemia da COVID-19, não é possível exigir do médico que use medicamentos prescritos precisamente para essa doença, enquanto esses não existirem. Por outro lado, nesse caso, deve ser considerado admissível que o médico prescreva o uso específico aos pacientes sob os seus cuidados, de medicamentos existentes e aprovados pelos órgãos regulatórios, necessariamente "off-label". Essa conduta será lícita se praticada de boa-fé, em dosagem adequada e com a segurança admissível em uma situação atípica como essa pandemia. Por isso, pode-se dizer que antivirais podem ser considerados como alternativas de possível uso, assim como medicamentos utilizados no tratamento das manifestações decorrentes da contaminação pela COVID-19, como, por exemplo, antibióticos (SOARES, 2020, p. 149).

Logo, conclui-se que quando o médico se depara com situações que demandam uma atuação de criatividade técnica (como a pandemia do coronavírus), não cometerá um ato ilícito quando prescrever ou administrar esses medicamentos "off-label".

Por outro lado, mesmo nessa situação, a responsabilidade do clínico não se extinguiria por "uma cláusula de não indenizar". O Código de Defesa do Consumidor, em seu artigo 25, veda a estipulação de cláusulas contratuais que "impossibilitem, exonerem ou atenuem a obrigação de indenizar". Portanto, “todas essas cláusulas exonerativas consideram-se não 
escritas e devem ser desconsideradas pelos respectivos usuários da prestação de serviços" (DENARI, 2001, p. 199).

No mesmo diapasão o diploma consumerista em seu artigo 51, inciso I, assegura que são nulas as cláusulas contratuais que "impliquem renúncia ou disposição de direitos", de modo, nos ditamos no artigo $6^{\circ}$, inciso VI, do referido diploma, é direito do consumidor a efetiva reparação dos danos materiais e morais que vier a sofrer.

Assim sendo, a responsabilidade civil do médico não pode ser extinta por uma “cláusula de não indenizar", que, como se viu, manifestamente será nula. Por tais motivos, não é possível, nessas relações, a estipulação de cláusula que restrinja um dever de reparação, uma vez que o paciente tem direito de ser inteiramente indenizado pelos danos sofridos.

Ao fim e ao cabo, a sinceridade, por meio de atitudes transparentes do médico, assim como a boa-fé são condutas essenciais para que se possa realizar o equilíbrio entre a necessária recepção do paciente, a fundamental técnica-médica, as obrigações e os limites das estruturas de atendimento em saúde, com o desígnio de sobrepujar a pandemia do melhor modo possível.

\section{CONSIDERAÇÕES FINAIS}

Compreende-se que a pandemia ocasiona provocações aos profissionais do Direito, exigindo interpretações e adaptações das normas viventes. As reflexões partem da responsabilidade civil contemporânea aplicada à atividade médica tendo como suas bases tanto o Código Civil quanto o Código de Defesa do Consumidor.

No que tange à espécie de obrigação pactuada entre o médico ou clínica médica e o paciente, constata-se que não há uma regra pronta sobre o que é aplicado, se apenas a obrigação de meio ou a obrigação de resultado, sendo possível a aplicação de ambas, a observar a natureza do serviço médico contratado, bem como os ditames contratuais estabelecidos entre o paciente e o profissional da medicina.

Nesse contexto de responsabilidade civil pós-moderna, os contornos tradicionais da responsabilidade civil sofrem interferências significativas. Como se não bastasse esse cenário, em face da pandemia do novo coronavírus, a aceitação de novas vicissitudes no confronto dessa crise gera vindouras soluções.

$\mathrm{O}$ ato médico de prescrever medicamentos é um ato complexo onde intervêm múltiplas variáveis que podem afetar a integridade profissional e a segurança do paciente. A frequência 
dos erros de medicação suscita a necessidade de estabelecer diretrizes adequadas de prevenção e cuidados, alicerçadas no fundamento ético da responsabilidade profissional, como o princípio da não maleficência.

A situação particular da indicação de medicamentos para outras patologias que não as autorizadas pelo órgão regulador governamental, merece regulamentação específica, para evitar, por um lado, a proliferação de prescrições desnecessárias e arriscadas, e, de outro, melhorar a qualidade de vida dos pacientes e o uso racional do medicamento.

O médico não pode preceituar ilusões. Ele receita fármacos, sob substrato técnico, que apresentem, ao menos, uma potencialidade benéfica ao paciente (sujeito de atendimento, e não item de laboratório). Ir de encontro a isso é ato antijurídico, que ensejará responsabilidade civil.

No atual cenário, entendeu-se que a responsabilidade médica no Direito brasileiro permanece sendo objetiva. O que muda, no panorama de tensão decorrente da pandemia da COVID-19, é um rigor ameno na apreciação da correção ou incorreção da conduta profissional na execução do ato médico.

\section{REFERÊNCIAS}

ANVISA. AGÊNCIA NACIONAL DE VIGILÂNCIA SANITÁRIA. Informações técnica n. 13 - Como a Anvisa vê o uso off label de medicamentos, 23 mai. 2005. Disponível em: http://portal.anvisa.gov.br/informacoes-tecnicas13. Acesso em: 11 de set. 2020.

BRASIL. Constituição da República Federativa do Brasil de 1988. Brasília, DF: Presidência da República. Disponível em: http://www.planalto.gov.br/ccivil_03/Constituicao/ Constituiçao.htm. Acesso em: 10 mai. 2020.

BRASIL. Lei $n^{o}$ 8.078, de 11 de setembro de 1990. Dispõe sobre a proteção do consumidor e dá outras providências. Disponível em:

http://www.planalto.gov.br/ccivil_03/Leis/L8078compilado.htm. Acesso em 10 mai. 2020.

BRASIL. Lei $n^{\circ}$ 10.406, de 10 de janeiro de 2002. Institui o Código Civil. Disponível em: http://www.planalto.gov.br/ccivil_03/leis/2002/L10406compilada.htm. Acesso em 19 mai. 2020.

BRASIL. Superior Tribunal de Justiça. $3^{\text {a }}$ Turma. REsp n. 364.168/SE. Rel. Min. Antônio de Pádua Ribeiro. Julgado em: 20 abr. 2004. Publicado em: DJU 21 jun. 2004, p. 215.

CAVALIERI FILHO, Sergio. Programa de responsabilidade civil. 4. ed. São Paulo: Malheiros, 2003.

CASTRONOVO, Carlo. Responsabilità Civile. Milão: Giuffrè Editora, 2018. 
CASTRO, João Monteiro de. Responsabilidade civil do médico. São Paulo: Método, 2005.

CÓDIGO DEONTOLÓGICO DA ORDEM DOS MÉDICOS. Regulamento de Deontologia

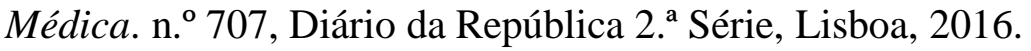

CONSELHO FEDERAL DE MEDICINA. Código de ética médica. Resolução CFM no 2217/18. Brasília: CFM; 2018.

CONSELHO FEDERAL DE MEDICINA. Resolução CFM $N^{o}$ 1.627/2001. Disponível em: https://sistemas.cfm.org.br/normas/visualizar/resolucoes/BR/2001/1627 Acesso em: 24 jul. 2020.

DENARI, Zelmo. Código Brasileiro de Defesa do Consumidor comentado pelos autores do anteprojeto: da qualidade de produtos e serviços, da prevenção e da reparação dos danos. In: GRINOVER, Ada Pellegrini et al. Código Brasileiro de Defesa do Consumidor comentado pelos autores do anteprojeto. 7. ed. São Paulo: Forense, 2001. cap. 4, p. 143-214.

DINIZ, Maria Helena. Curso de Direito Civil Brasileiro. v. 7. Responsabilidade Civil. 21. ed. São Paulo: Saraiva, 2013.

DONNINI, Rogério Ferraz. Responsabilidade pós-contratual no novo Código Civil e no Código de Defesa do Consumidor. São Paulo: Saraiva, 2004.

ESTADOS UNIDOS DA AMÉRICA. Martha L. Klein v. Robert S. Biscup. Case 1996-0798. Disponível em: http://www.supremecourt.ohio.gov/Clerk/ecms/\#/caseinfo/1996/0798. Acesso em: 24 jul. 2020.

GOLDIM, José Roberto. COVID-19 e o Uso Compassivo ou Off-Label de Medicamentos: Bioética complexa. Disponível em: https://bioeticacomplexa.blogspot.com/2020/04/covid-19e-o-uso-compassivo-ou-off.html?m=1. Acesso em: 23 jul. 2020.

GONÇALVES, Carlos Roberto. Responsabilidade civil. 8. ed. São Paulo: Saraiva, 2003.

GUTIÉRREZ, Graciela N. Messina de Estrella. La Responsabilidad Civil en La Era Tecnológica. tendências y prospectivas. Buenos Aires: Abeledo-Perrot, 1997.

MARQUES, Cláudia Lima; BENJAMIN, Antônio Herman; MIRAGEM, Bruno.

Comentários ao Código de Defesa do Consumidor. São Paulo: Revista dos Tribunais, 2004.

MATIELO, Fabricio Zamprogna. Responsabilidade Civil do Médico. 2. ed. Porto Alegre: Sagra Luzzato, 1998.

MORAES, Maria Celina Bodin de. Danos à pessoa humana: uma leitura civil-constitucional dos danos morais. Rio de Janeiro: Renovar, 2003.

NERY JUNIOR, Nelson. Código Brasileiro de Defesa do Consumidor comentado pelos autores do anteprojeto: da proteção contratual. In: GRINOVER, Ada Pellegrini et al. Código 
Brasileiro de Defesa do Consumidor comentado pelos autores do anteprojeto. 7. ed. São Paulo: Forense, 2001. cap. 6, p. 441-570.

NERY JUNIOR, Nelson; NERY, Rosa Maria de Andrade. Código Civil comentado e legislação extravagante. 3. ed. São Paulo: Revista dos Tribunais, 2005.

NUNES, Luiz Antonio Rizzatto. Comentários ao Código de Defesa do Consumidor. São Paulo: Saraiva, 2000.

PEREIRA, André Gonçalo Dias. Prescrição médica "off-label” e COVID-19: uma reflexão ético-jurídica. Actualidad Jurídica Iberoamericana, n. 12, mayo/2020. Edición Semestral, Valência, Espanha, 2020, p. 136-143.

PEREIRA, Caio Mario da Silva. Teoria Geral Das Obrigações. v. 2. Rio de Janeiro: Ed. Forense, 1993.

SCHREIBER, Anderson. Novos paradigmas da responsabilidade civil. São Paulo: Atlas, 2013.

SOARES, Flaviana Rampazzo. Prescrição de medicamentos "off-label" no direito brasileiro: responsabilidade médica e desafios em tempos de COVID-19. Actualidad Jurídica Iberoamericana, n. 12, mayo/2020. Edición Semestral, Valência, Espanha, 2020, p. 144-153.

TUNC, André. La responsabilité civile. 2. ed. Paris: Economica, 1989.

VENOSA, Sílvio de Salvo. Direito civil: responsabilidade civil. 3. ed. São Paulo: Atlas, 2003. v. 4. 